\title{
Distribution and origin of biologically available phosphorus in the water of the Meiliang Bay in summer
}

\author{
HUANG Qinghui ${ }^{1,2}$, WANG Zijian ${ }^{1}$, WANG Donghong ${ }^{1}$, MA Mei ${ }^{1} \&$ WANG Chunxia ${ }^{1}$ \\ 1. State Key Laboratory of Environmental Aquatic Chemistry, Research Center for Eco-Environmental Sciences, Chinese \\ Academy of Sciences, Beijing 100085, China; \\ 2. Key Laboratory of Yangtze Aquatic Environment (Ministry of Education), College of Environmental Science and Engineering, \\ Tongji University, Shanghai 200092, China \\ Correspondence should be addressed to Wang Zijian or Huang Qinghui (email: wangzj@mail.rcees.ac.cn or qhhuang@mail. \\ tongji.edu.cn)
}

Received September 16, 2005; accepted February 6, 2006

\begin{abstract}
The investigation and continuous monitoring with an innovative iron oxide embedded cellulose acetate membrane (FeO/CAM) on the concentrations of biologically available phosphorus (BAP) were conducted in the Meiliang Bay of the Taihu Lake during summer in 2004. The results showed that the concentrations of dissolved (FeO-DP), particulate (FeO-PP) and total bioavailable phosphorus (FeO-P) had similar horizontal distribution. The BAP concentrations were the highest in those estuaries in the northern bay. With the decrease of the distance to the estuary or long shore, there was little difference between BAP concentrations in an open lake area. During the observation period, algal blooms occurred in most waters of the northern bay, which was reflected from the high concentrations of chlorophyll a (Chl-a). While they were not highest in the estuarine waters of those major rivers, this is the case for the BAP concentrations. The concentrations of Chl-a had a significantly positive correlation with those of bioavailable phosphorus in the open area of the Meiliang Bay. With the sediment resuspension induced by wind and wave, BAP concentrations increased in a short-term, indicating that the riverine $\mathrm{P}$ inputs mainly contribute to the concentrations of BAP in the estuarine water while internal $P$ release was the major source of BAP in the open lake area. In the eutrophic shallow lake, the blooms of alga may cause $\mathrm{pH}$ increase and further result in internal $\mathrm{P}$ release. The above results showed that the new membrane of FeO/CAM can be used to monitor the concentrations of BAP and provide the scientific justifications for the control strategy of the lake eutrophication.
\end{abstract}

Keywords: phosphorus, bioavailability, eutrophication, resuspension, Taihu Lake.

In the developed region of the middle and lower reaches of the Yangtze River, many shallow lakes such as the Taihu Lake and the Chaohu Lake are facing the problem of eutrophication. Phosphorus is usually the key factor causing the eutrophication in these lakes.
Therefore, the control of phosphorus is critical for the elimination of the eutrophication in the shallow lakes $^{[1]}$. Moreover, on the condition that the external $\mathrm{P}$ loadings are abated and controlled, it is very necessary for us to control the internal P loadings considering the 
sediment release ${ }^{[2,3]}$. The dredging of sediment $t^{[4,5]}$ and the addition of the $\mathrm{Fe} / \mathrm{Al}$ salts ${ }^{[6,7]}$ may be the effective abatement measures. Therefore, against lake eutrophication, it is important to understand completely the distribution of bioavailable phosphorus (BAP) ${ }^{[8]}$ in the water and sediment.

Meiliang Bay is the major source of drinking water of the resident in Wuxi City. There are several water supply works, e.g. Meiyuan, Qianlongkou, Chongshan, Mashan near the Meiliang Bay of the Taihu Lake. However, many domestic sewage and industrial wastewater from surrounding cities attributes major parts of heavy metals and nutrients through three main rivers such as Liangxi River (R3, see Fig.1), Zhihugang River (R2) and Wujingang River (R1) ${ }^{[9]}$. Although the abatement of wastewater was increasingly reinforced, the algal blooms still occur frequently every summer ${ }^{[10]}$, which will threaten the safety of the supply of drinking water of Wuxi citizen. In the eutrophic water, the concentration of BAP usually is very low. Generally, it can be determined by using iron oxide impregnated filter paper as $\mathrm{P} \operatorname{sink}^{[11]}$. Our research group improved this method by iron oxide embedded cellulose acetate membrane (FeO/CAM, China Patent AN: 200410030764.1). This paper aimed to understand the spatio-temporal distribution of BAP concentrations in the Meiliang Bay with this new membrane material. Based on this, the sources of BAP in the water were also discussed in order to make strategy for effective control on BAP concentrations.

\section{Materials and methods}

\subsection{Sample collection and field observation}

(i) Planar survey. Sampling site locations (28 sites in Fig. 1) were predetermined according to the grids in the Meiliang Bay of the Taihu Lake and corrected in situ with Magellan GPS315 (Taiwan, China). Site $0^{\#}$ lied in water intake of the Qianglongkou Supply Water Plant, and site $1^{\#}$ was located in the Liangxi River estuary in the Wuli Lake, and site $7^{\#}$ was situated near the estuaries of two main rivers. The water samples were collected from surface and bottom levels on June 12th, 2004. Water temperature, $\mathrm{pH}$, dissolved oxygen (DO) and electrical conductivity (EC) of the water samples were measured in situ with a portable sen- sion $^{\mathrm{TM}} 156$ Multi-parameter Meter (Hach Co., USA). Each sample was kept at $4^{\circ} \mathrm{C}$ in an insulated Igloo box (Aldrich Co., USA) in the fields, and then transported to the laboratory by motorboat in $4 \mathrm{~h}$. The concentrations of chlorophyll $a$ and different species of BAP were determined for these water samples.

(ii) Continuous monitoring. One-week continuous monitoring was carried out under a trestle in Taihu station (Fig.1) from July 16-23, 2004. The self-made $\mathrm{FeO} / \mathrm{CAM}^{[12]}$ pieces $(4 \mathrm{~cm} \times 5 \mathrm{~cm})$ were protected by polyethylene mesh screen, then they were placed in the surface and bottom of the water column ( 3 pieces per layer) under the trestle. The $\mathrm{FeO} / \mathrm{CAM}$ pieces, which were used for monitoring the daily averaged concentrations of BAP in the water, were taken out to determinate and replaced by a new batch of $\mathrm{FeO} / \mathrm{CAM}$ pieces once every $24 \mathrm{~h}$. In addition, the surface and bottom water samples were also collected at 9:00 every morning to determine water temperature, $\mathrm{pH}$, $\mathrm{DO}$ and $\mathrm{EC}$, and also to determine real-time concentrations of BAP in the water (thrice).

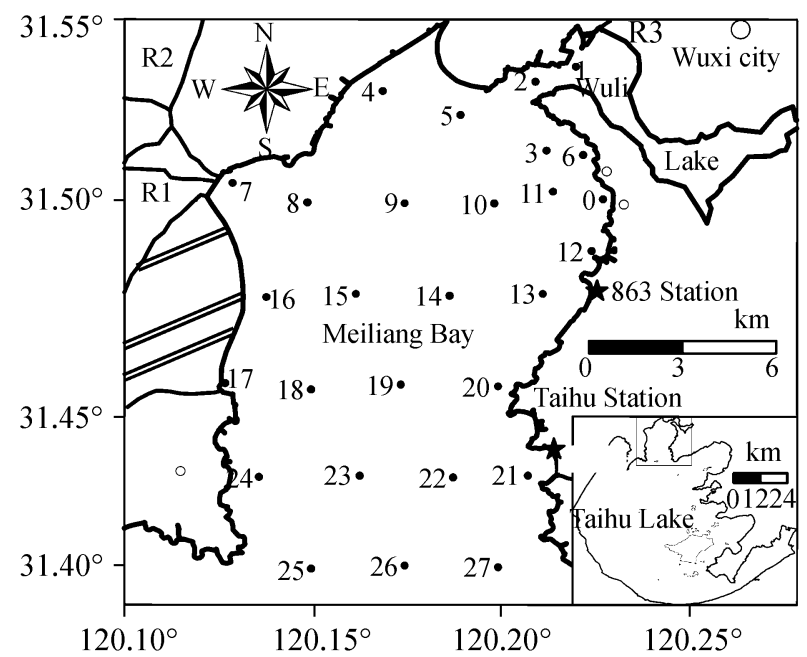

Fig. 1. Sample site distribution in the Meiliang Bay. R1, Wujingang River; R2, Zhihugang River; R3, Liangxi River.

\subsection{Laboratory analysis}

Each water sample from the planar survey was separated into two parts: one part was immediately filtered using $0.45 \mu \mathrm{m}$ cellulose acetate filter membranes after sampling. Each filter membrane trapping particles was frozen in a zipper bag at $-20^{\circ} \mathrm{C}$ until it was analyzed for chlorophyll $a$ extracted by $90 \%$ ace- 
tone $^{[13]}$. The filtered water samples were used for the determination of dissolved bioavailable phosphorus (FeO-DP) concentrations with $\mathrm{FeO} / \mathrm{CAM}$ method. Another part of unfiltered water was used to determine total concentrations of bioavailable phosphorus (FeO-P) in the water. Particulate bioavailable phosphorus (FeO-PP) in the water was obtained as the difference between FeO-P and FeO-DP concentrations.

As far as water samples collected from monitoring site were concerned, the real-time concentrations of BAP were determined using $\mathrm{FeO} / \mathrm{CAM}$ method. The $\mathrm{FeO} / \mathrm{CAM}$ pieces collected from the field were used for the determination of phosphorus enriched in $24 \mathrm{~h}$, and then the daily averaged concentrations of BAP were calculated. Determination procedure was described as follows:

Filtered or unfiltered water sample of $80 \mathrm{~mL}$ was shaken with a $\mathrm{FeO} / \mathrm{CAM}$ strip for $16 \mathrm{~h}\left(25^{\circ} \mathrm{C}\right)$. And then each $\mathrm{FeO} / \mathrm{CAM}$ strip was shaken in $25 \mathrm{~mL}$ of 0.1 $\mathrm{mol} / \mathrm{L} \mathrm{H}_{2} \mathrm{SO}_{4}$ solution for $1 \mathrm{~h}$ in order to release the adsorbed $\mathrm{P}$ from the membrane. $\mathrm{FeO} / \mathrm{CAM}$ strips were taken out, and rinsed with water. The $\mathrm{pH}$ value of elution solution should be adjusted to neutral before the determination of phosphate using the molybdenum blue spectrophotometric method ${ }^{[14]}$. Deionized water instead of real water sample was used to do a whole experiment as operational blank. The experiments of $\mathrm{FeO} / \mathrm{CAM}$ strips collected from field during the monitoring period directly began from the elution step, and the procedure was described as above.

\subsection{Data analysis}

Data were analyzed with mathematic statistics and

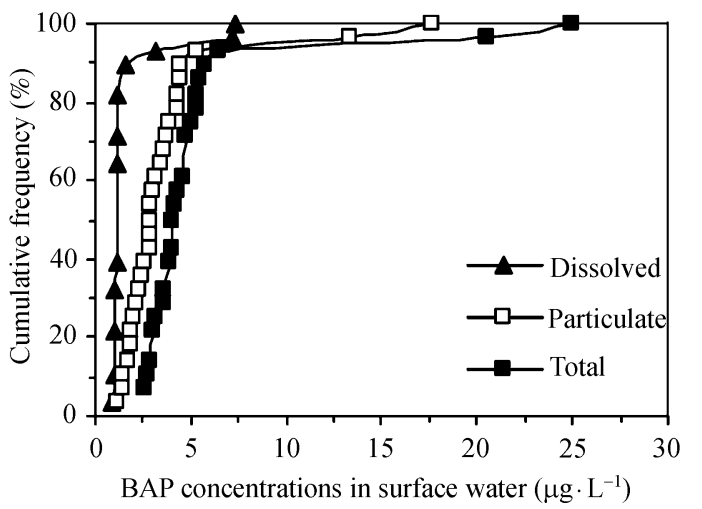

geostatistical methods. Cumulative frequency and correlation analysis were carried out by using SPSS 11.0 (Lead technology co.); semi-variance analysis was done in geostatistical software GS+ 5.0 (Gamma Design Ltd. Co.); the contour maps were drawn by kriging grid method in Surfer 7.0 software (Golden Software Ltd. Co.).

\section{Results and discussion}

2.1 Distribution of the concentrations of BAP and chlorophyll a in the water of the Meiliang Bay

Maximum of total BAP concentrations were up to $25.0 \mu \mathrm{g} / \mathrm{L}$ in surface water and $40.2 \mu \mathrm{g} / \mathrm{L}$ in bottom water, but they were low in most waters of the Meiliang Bay. For examples, at about $90 \%$ of sampling sites, there were lower than $5.0 \mu \mathrm{g} / \mathrm{L}$ of total BAP in surface water and lower than $10 \mu \mathrm{g} / \mathrm{L}$ of total BAP in bottom water as shown in Fig. 2. The concentration of dissolved BAP was higher than that of particulate BAP in the water at site $0^{\#}$, which is close to the intake of the Qianlongkou Water Supply Works. However, in the water at other sites, the concentrations of dissolved BAP were lower than those of particulate BAP. Particulate BAP concentrations in surface water and bottom water accounted for $69 \%, 76 \%$ of total BAP concentrations, respectively. It indicated that BAP in the suspended particles had an important contribution to algal growth. It was similar with the results that BAP concentrations in the particles were well related to the contents of reactive, non-apatite inorganic phosphorus fractions $^{[15]}$.

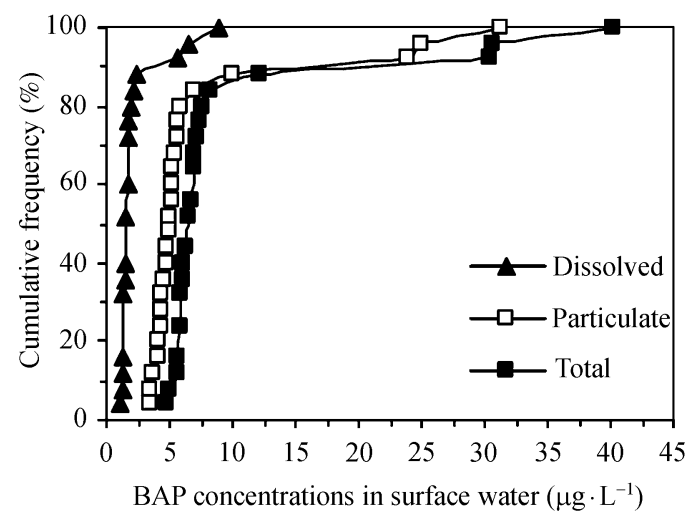

Fig. 2. Cumulative frequency distribution of the concentrations of different BAP species in the water. 
As presented in Table 1, the ratio of nugget/sill from semi-variance analysis is less than $25 \%$. It was shown that the spatial variability of BAP concentrations was not caused directly by external random factors such as sampling or experimental error, but caused by spatial structural factors. That is to say, it is dependent upon the spatial variation of phosphorus input from rivers and internal phosphorus release. In both surface and bottom water of the Meiliang Bay, there was a significant correlation between various BAP species $(r=0.52-1.00, p<0.01)$. The horizontal distributions of the concentrations of both dissolved BAP and particulate BAP were very similar to those of total BAP in the waters of the Meiliang Bay (Fig. 3). There were high BAP concentrations in the waters near the major estuaries of Zhihugang River and Wujingang River in the northwest and Liangxi River in the northeast. It is clear that riverine $\mathrm{P}$ input is the direct reason to high BAP concentrations in the water of estuaries. Our previous work showed that the distribution of reactive phosphorus fractions in the surface sediment was determined by long-term external $\mathrm{P}$ inputs $^{[16]}$, while the concentrations of BAP were mainly contributed by reactive $P$ fractions in the sediments ${ }^{[17]}$. The horizontal distribution of BAP concentrations in the water was also similar to that in the sediment ${ }^{[18]}$ in the Meiliang Bay. This indicated that BAP concentrations in the overlying water column were well related to those in the sediments. That is to say, BAP in the water is largely due to phosphorus release from the sediments.

As shown in Fig. 4, there were low levels of chlorophyll $a$ near the major estuaries and the mouth of Meiliang Bay, while there were high levels of chloro-

Table 1 Semi-variance analysis of bioavailable phosphorus and chlorophyll $a$ in the water

\begin{tabular}{|c|c|c|c|c|c|c|c|}
\hline Parameters & Model & $\begin{array}{l}\text { Range } \\
(\mathrm{km})\end{array}$ & $\begin{array}{c}\text { Nugget } \\
\text { variance } \mathrm{C}_{0}\end{array}$ & $\begin{array}{c}\text { Sill variance } \\
\mathrm{C}_{0}+\mathrm{C}\end{array}$ & $\begin{array}{c}\text { Ratio Nugget/Sill } \\
\mathrm{C}_{0} /\left(\mathrm{C}_{0}+\mathrm{C}\right)\end{array}$ & $\begin{array}{c}\text { Regression } \\
\text { coefficient } R^{2}\end{array}$ & $\begin{array}{c}\text { Spatial dependence } \\
\text { level }\end{array}$ \\
\hline FeO-P at surface & spherical & 21.8 & 0.0497 & 0.3604 & $13.8 \%$ & 0.732 & strong \\
\hline FeO-P at bottom & spherical & 41.4 & 0.0090 & 1.0580 & $0.9 \%$ & 0.604 & strong \\
\hline Chl- $a$ at surface & spherical & 28.8 & 0.025 & 2.060 & $1.2 \%$ & 0.822 & strong \\
\hline Chl- $a$ at bottom & linear & 20.0 & 0.001 & 2.010 & $0.0 \%$ & 0.789 & strong \\
\hline
\end{tabular}

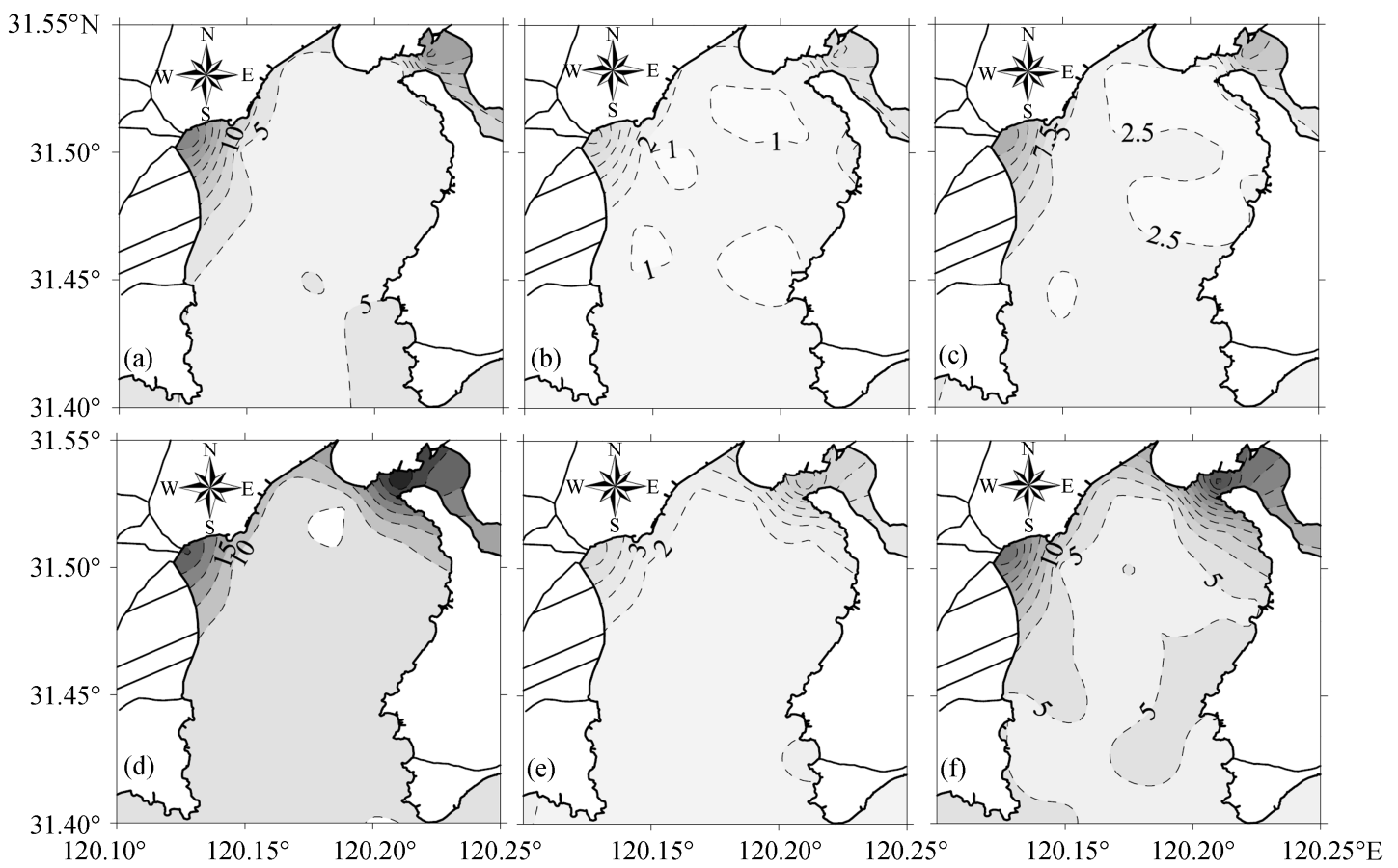

Fig. 3. Distribution of various species of bioavailable phosphorus in the water of the Meiliang Bay. Surface: (a)Total; (b) dissolved; (c) particulate; bottom: (d) total; (e) dissolved; (f) particulate; Unit: $\mu \mathrm{g} / \mathrm{L}$. 


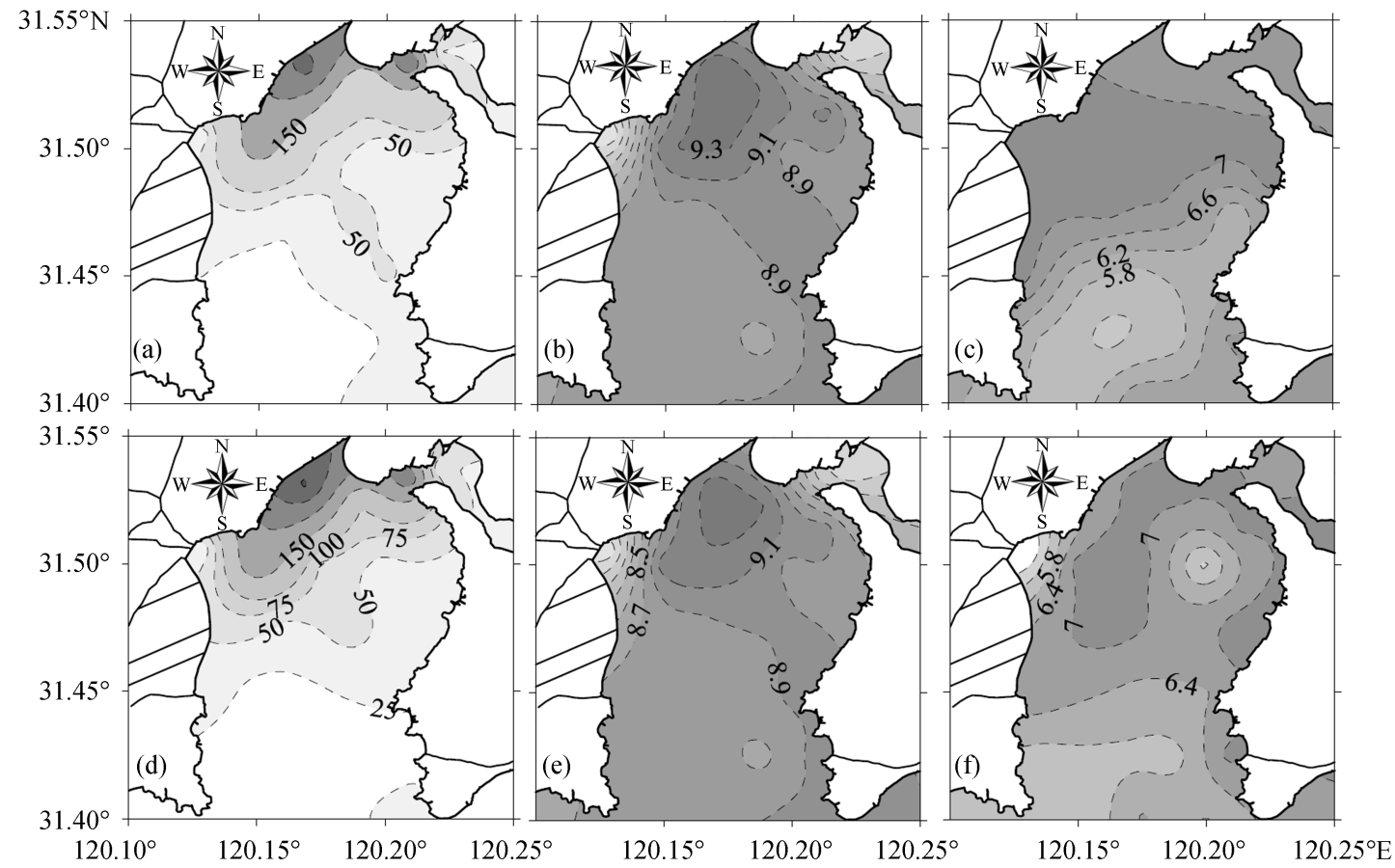

Fig. 4. Distribution of Chl- $a, \mathrm{pH}, \mathrm{DO}$ in the water of the Meiliang Bay. Surface: (a) Chl- $a(\mu \mathrm{g} / \mathrm{L})$; (b) pH; (c) DO (mg/L); bottom: (d) Chl- $a$ ( $\mu \mathrm{g} / \mathrm{L})$; (e) $\mathrm{pH}$; (f) $\mathrm{DO}(\mathrm{mg} / \mathrm{L})$.

phyll $a(>100 \mu \mathrm{g} / \mathrm{L}$, up to $328 \mu \mathrm{g} / \mathrm{L})$ in the waters of the bayhead of Meiliang Bay and the mouth of Wuli Lake, where cyanobacteria blooms occurred. Algal consumed carbon dioxide and produce oxygen through the photosynthesis, which could cause $\mathrm{pH}$ increase. Simultaneously, the concentrations of dissolved oxygen increased. There were high levels of $\mathrm{pH}$ and chlorophyll $a$ in the same water area, where the concentrations of dissolved oxygen were slightly higher than those in other water areas as shown in Fig.4. It is similar to the observation outside the Changjiang Estuary ${ }^{[19]}$. The deficiency of dissolved oxygen occurred in the waters from the south of Sanshan Island to the mouth of Meiliang Bay (Fig. 4), where algal growth could be limited by low concentrations of BAP (Fig. 3). Chlorophyll a would decompose during the sedimentation of biological detritus, which consumed oxygen and caused the dissolved oxygen deficient. However, the deficiency of dissolved oxygen also occurred in the bottom water of the estuaries in northwest Meiliang Bay as shown in Fig. 4, where photosynthesis of algal was limited due to the impact of river inputs and respiration was dominant in the metabolism of alga.

\subsection{Relation between chlorophyll a and bioavailable phosphorus concentrations in the water}

The concentrations of chlorophyll $a$ in the water of the estuaries entering lake, where bioavailable phosphorus was high, were not higher than those in the water of the bayhead of Meiliang Bay (Fig. 4). Generally, hydrodynamic process was strong in the estuarine zone. The sediments were easily disturbed and resuspended so that water transparency could be reduced. In addition, riverine suspended particles caused the increase of optical attenuation coefficient of estuarine water $^{[20]}$. Accordingly, the photosynthesis of phytoplankton was affected. That is to say, primary production was not high. Even though this, the probability that it could be source scene of algal blooms could not be excluded for the moment. There was a small clockwise circumfluence in the bayhead of the Meiliang Bay after inning, so the exchange of the water with outside was reduced ${ }^{[20]}$. Furthermore, there was abundant bioavailable phosphorus, which was in favor of primary production. Otherwise, the horizontal distribution of phytoplankton was influenced by wind speed and wind direction ${ }^{[21]}$, so the algae was likely to 
accumulate in the bayhead with excursion following water current due to storm waves ${ }^{[22]}$. For example, when the algal blooms broke out in the late July in 1990, the algae blanket, $0.5 \mathrm{~m}$ thick, accumulated in the bankside of the north part of the Meiliang Bay ${ }^{[20]}$. Such echo process inside and outside made algae bloom in bayhead waters with high chlorophyll $a$ concentrations. Algae continually absorbed nutrient so that nutrient concentrations were obviously reduced in local area sometimes ${ }^{[23]}$. Therefore, lower levels of BAP were found near the Sanshan Island in the center of the North Meiliang Bay as shown in Fig. 3. During the survey period in June, water temperature was $23-$ $25^{\circ} \mathrm{C}$, which is just fit for the growth of Microcystis aeruginosa $^{[24]}$.

As far as the whole Meiliang Bay was concerned, the concentrations of chlorophyll $a$ had no significant correlation with those of bioavailable phosphorus (Table 2). However, the concentrations of chlorophyll $a$ had significant correlation $(r=0.792, p<0.01)$ with those of BAP in those waters far from the estuaries and the bay head, where there was less influence by external inputs. The correlation coefficient was 0.934 $(p<0.01)$ in bottom water where rich BAP was originated from internal sources. However, there was no significant correlation between Chl- $a$ and BAP in the surface water, because algae growth was limited due to the supply of BAP less than algae absorption of BAP. Therefore, the bioavailability of phosphorus of internal sources is the major limiting factor for the phytoplankton in the open lake area.

In the waters near the mouth of Meiliang Bay, especially in the southeast waters, the concentrations of both bioavailable phosphorus and chlorophyll $a$ were lower than those in other waters as shown in Figs. 3 and 4 . The low levels of bioavailable phosphorus were due to less mud. The growth of the algae was limited by low levels of bioavailable phosphorus and strong hydrodynamic process. It was in accordance with the results from the discussion of the relationship between sediment phosphorus capability and eutrophication risk induced by phosphorus release ${ }^{[25]}$. Additionally, the algal biomass in the Meiliang Bay could be reduced by the water exchange between Meiliang Bay and central Taihu Lake due to wind field in sum$\operatorname{mer}^{[26]}$.

\subsection{Dynamic change of bioavailable phosphorus in the water of Meiliang Bay in summer}

The averaged concentrations of BAP in 42 membrane samples, which were directly collected from the surface and bottom water column during 7-day continuous monitoring period, was $0.11 \mu \mathrm{g} / \mathrm{cm}^{2}$. The concentrations of BAP in 42 water samples simultaneously collected, which varied from $6.9 \mu \mathrm{g} / \mathrm{L}$ to 8.8 $\mu \mathrm{g} / \mathrm{L}$, were averaged as $7.5 \mu \mathrm{g} / \mathrm{L}$. Hereby the transform factor $(f)$ of the concentrations of BAP between membrane and water was calculated as $68.2 \mathrm{~cm}^{2} / \mathrm{L}$, and then the concentrations of BAP enriched in the membrane every $24 \mathrm{~h}$ can be estimated. In the monitoring period, the daily averaged concentrations of BAP in the water varied between $3.8 \mu \mathrm{g} / \mathrm{L}$ and 12.6 $\mu \mathrm{g} / \mathrm{L}$ and the concentrations of BAP were averaged as $7.5 \mu \mathrm{g} / \mathrm{L}$ in this week. Due to the disturbance of storm and windwave occurring from the evening of 19 July to next morning, many particles were resuspended from the bottom sediment and more BAP was released to water ${ }^{[27,28]}$. As a result of sediment resuspension, water became turbid and light penetration became weak so that the algae stopped to grow or died. Bioavailable phosphorus accumulated in the water cannot be consumed timely by the algae so that the concentrations of BAP could increase as shown in Fig. 5. It is obvious that sediment resuspension has great influence on internal $P$ release and water transparency, and further on primary production. Water surface was calm after the storm and the dead algae particles gradually settled down, and then they were minerali-

Table 2 Correlation between chlorophyll $a$ and BAP concentrations in the water of the Meiliang Bay

\begin{tabular}{cllc}
\hline Sampling location & \multicolumn{1}{c}{ Layer } & \multicolumn{1}{c}{ Correlation equations } & $r$ \\
\hline Meiliang Bay & surface + bottom & {$[$ Chl- $a]=1.2791 \times[\mathrm{FeO}-\mathrm{P}]+52.467$} & 0.140 \\
Open area of Meiliang Bay $\left.{ }^{\mathrm{a}}\right)$ & surface + bottom & {$[\mathrm{Chl}-a]=5.2364 \times[\mathrm{FeO}-\mathrm{P}]+6.4745$} & $0.792^{* *}$ \\
Open area of Meiliang Bay ${ }^{\mathrm{a}}$ & surface & {$[\mathrm{Chl}-a]=-5.5418 \times[\mathrm{FeO}-\mathrm{P}]+60.136$} & -0.243 \\
Open area of Meiliang Bay ${ }^{\mathrm{a}}$ & bottom & {$[\mathrm{Chl}-a]=5.8861 \times[\mathrm{FeO}-\mathrm{P}]-5.459$} & $0.934^{* *}$ \\
\hline
\end{tabular}

a) Not including five sites $\left(1^{\#}, 4^{\#}, 5^{\#}, 7^{\#}, 8^{\#}\right)$ in estuaries and bayhead; ** significance at $\alpha=0.01$ level. 
zed or decomposed. Nutrient released from those processes could be utilized again by palingenetic algae $^{[2,3]}$, so the concentrations of BAP decreased at the end of monitoring period as shown in Fig. 5. Therefore, iron oxide embedded cellulose acetate membrane has good potential to monitor the change of BAP concentrations in the water.

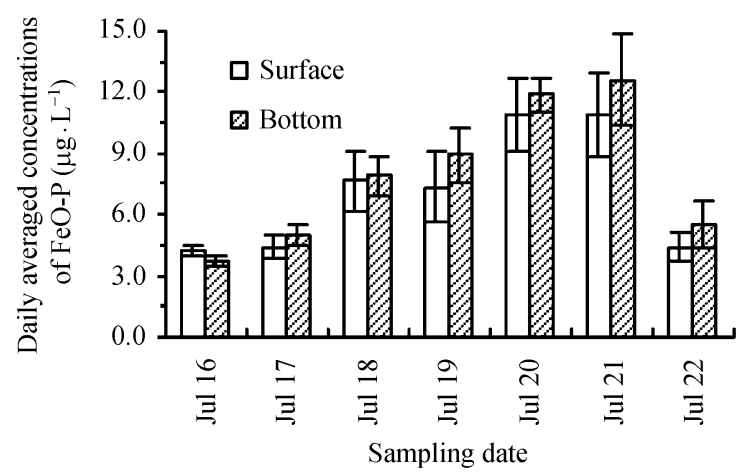

Fig. 5. Change of daily averaged concentrations of bioavailable phosphorus in the water at Taihu station.

\section{Conclusion}

In a shallow eutrophic lake, algal blooms can cause sediment phosphorus release by increasing $\mathrm{pH}$. Internal $\mathrm{P}$ release is the main source of BAP in the open area of Meiliang Bay, where the concentration of BAP may be the main limiting factor of phytoplankton growth. However, in the estuaries of north Meiliang Bay, there is much external BAP. Hydrodynamic processes such as river/lake water mixing and sediment resuspension can cause the increase of turbidity or the decrease of transmittance so as to affect phytoplankton synthesis and limit the primary production. The reduction of BAP concentrations may still be an effective approach to the abatement and control of eutrophication in natural water, although the occurrence of lake eutrophication has various causes. Therefore, effective measures must be taken to monitor the dynamic change of BAP concentrations in the water so as to reduce BAP concentrations and ultimately solve the problem of lake eutrophication.

Acknowledgements The authors would like to give thanks to those colleagues in the Research Station of Taihu Lake Ecosystem of the Chinese Academy of Sciences. This work was supported by the Knowledge Innovation Project of the Chinese Academy of Sciences (Grant No. KZCX1SW-12-II-32).

\section{References}

1. Schindler, D. W., Eutrophication and recovery in experimental lakes: implications of lake management, Science, 1974, 184: 897 -898 .

2. Qin, B. Q., Hu, W. P., Gao, G. et al., Dynamics of sediment resuspension and the conceptual schema of nutrient release in the large shallow Lake Taihu, China, Chinese Science Bulletin, 2004, 49(1): $54-64$.

3. Gao, G., Qin, B. Q., Zhu, G. W. et al., Seasonal variation of alkaline phosphatase activity in Meiliang Bay, Lake Taihu, Journal of Lake Sciences (in Chinese), 2004, 16(3): 245-251.

4. Pu, P. M., Wang, G. X., Hu, W. P. et al., Can we control lake eutrophication by dredging? Journal of Lake Sciences (in Chinese), 2000, 12(3): 269-279.

5. Fan, C. X., Zhang, L., Wang, J. J. et al., Processes and mechanism of effects of sludge dredging on internal source release in lakes, Chinese Science Bulletin, 2004, 49(17): 1853-1859.

6. Sherwood, L. J., Qualls, R. G., Stability of phosphorus within a wetland soil following ferric chloride treatment to control eutrophication, Environ. Sci. Technol., 2001, 35(20): 4126-4131.

7. Lewandowski, J., Schauser, I., Hupfer, M., Long term effects of phosphorus precipitations with alum in hypereutrophic Lake Susser See (Germany), Water Research, 2003, 37(13): $3194-$ 3204.

8. Gerdes, P., Kunst, S., Bioavailability of phosphorus as a tool for efficient $\mathrm{P}$ reduction schemes, Water Science and Technology, 1998, 37(3): 241-247.

9. Qu, W. C., Dickman, M., Wang, S. M., Multivariate analysis of heavy metal and nutrient concentrations in sediments of Taihu Lake, China, Hydrobiologia, 2001, 450: 83-89.

10. Chen, Y. W., Fan, C. X., Teubner, K. et al., Changes of nutrients and phytoplankton chlorophyll- $a$ in a large shallow lake, Taihu, China: an 8-year investigation, Hydrobiologia, 2003, 506: 273279.

11. Sharpley, A. N., An innovative approach to estimate bioavailable phosphorus in agricultural runoff by Fe oxide impregnated paper, J. Environ. Qual., 1993, 22: 597-601.

12. Huang, Q. H., Wang, D. H., Ma, M. et al., New method to assess phosphorus bioavailability in the sediments and soils, Environmental Science (in Chinese), 2005, 26(2): 206-208.

13. Wetzel, R. G., Likens, G. E., Limnological Analyses, 3 Ed., New York: Springer-Verlag, 2000, 1-429.

14. Murphy, J., Riley, J. P., A modified single solution method for the determination of phosphate in natural waters, Anal. Chim. Acta, 1962, 27: $31-36$.

15. DePinto, J. V., Young, T. C., Martin, S. C., Algal-available phosphorus in suspended sediments from lower Great Lakes tributaries, J. Great Lakes. Res., 1981, 7(3): 311-325.

16. Huang, Q. H., Wang, Z. J., Wang, D. H. et al., Origins and mobility 
of phosphorus forms in the sediments of Lakes Taihu and Chaohu, China, J. Environ. Sci. \& Health, Part A, 2005, 40(1): 91-102

17. Zhu, G. W., Qin, B. Q., Gao, G. et al., Fraction of phosphorus in sediments and its relation with soluble phosphorus contents in shallow lakes located in the middle and lower Changjiang River, China, Acta Scientiae Circumstantiae (in Chinese), 2004, 24(3): $381-388$

18. Huang, Q. H., Wang, Z. J., Wang, D. H. et al., Environmental soil phosphorus testing and phosphorus mobility in Taihu Lake, China, Pedosphere, 2004, 14(4): 461-466.

19. Zhu, J. R., Distribution of chlorophyll-a off the Changjiang River and its dynamic cause interpretation, Science in China, Series D, 2005, 48(7): 950-956.

20. Qin, B. Q., Hu, W. P., Chen, W. M. et al., Evolvement Process and Mechanism of Aquatic Environment of the Taihu Lake (in Chinese), Beijing: Science Press, 2004, 1-389.

21. Chen, Y. W, Qin, B. Q., Teubner, K. et al., Long-term dynamics of phytoplankton assemblages: Microcystis-domination in Lake Taihu, a large shallow lake in China, Journal of Plankton Research, 2003, 25(4): 445-453.

22. Fan, C. X., Chen, Y. W., Wu, Q. L., Effect of prevailing wind in summer on distribution of algal bloom in Lake Taihu, Shanghai Huanjing Kexue (in Chinese), 1998, 17(8): 4-6.

23. Huang, Y. P., Aquatic Environment and Pollution Control of the Taihu Lake (in Chinese), Beijing: Science Press, 2001.

24. Yang, D. T., Chen, W. M., Jiang, J. et al., Effects of algal bloom on N, P and $\mathrm{K}$ contents in Meiliang Bay of Taihu Lake. Chinese Journal of Applied Ecology (in Chinese), 2003, 14(6): 969-972.

25. Huang, Q. H., Wang, Z. J., Wang, D. H. et al., Phosphorus sorption capacity of the surface sediment in the Lake Taihu and risk assessment of phosphorus release, Journal of Lake Sciences (in Chinese), 2004, 16(2): 97-104.

26. Qin, B. Q., Hu, W. P., Chen, W. M. et al., Studies on the Hydrodynamic Processes and Related Factors in Meiliang Bay, Northern Taihu Lake, China, Journal of Lake Sciences (in Chinese), 2000, 12(4): $327-334$.

27. Fan, C. X., Zhang, L., Qu, W. C., Lake sediment resuspension and caused phosphate release: a simulation study, Journal of Environmental Sciences, 2001, 13(4): 406-410.

28. Fan, C X, Zhang, L., Qin, B. et al., Estimation on dynamic release of phosphorus from wind-induced suspended particulate matter in Lake Taihu, Science in China, Series D, 2004, 47(8): 710-719. 